\title{
The Role of Corrugation Die Parameters on the Mechanical Properties of Aluminum Alloy (AA 5083) Processed by Repetitive Corrugation and Straightening
}

\author{
N. Thangapandian, S. Balasivanandha Prabu* \\ Department of Mechanical Engineering, College of Engineering Guindy, Anna University, Chennai, India \\ Email: "sivanandha@annauniv.edu
}

Received 14 May 2015; accepted 23 July 2015; published 30 July 2015

\begin{abstract}
The microstructure and mechanical properties of aluminium alloy (AA 5083) processed through Repetitive Corrugation and Straightening (RCS) was studied. The RCS process consists of corrugating a flat specimen with a pair of systematically grooved dies and straightening was done with two parallel flat dies. The aluminium samples were subjected to RCS process using two different die: Die I-semi grooved die with breath $=$ height $=5 \mathrm{~mm}$ and $\theta=30^{\circ}$ and Die II-semicircular profile with radius $=10 \mathrm{~mm}$. The specimens were subjected to maximum 8 passes for die $I$ but the other one went upto 14 pass. The grain refinement was studied from the microstructure examination using TEM. The mechanical properties such as tensile strength, hardness and the grain size were compared. The tensile strength and hardness were found increasing with respect to the number of passes. The tensile strength increased $25 \%$ in the sixth pass when compared to the parent material. But the strength and hardness values were reduced at 8th pass due to the surface cracks. The TEM studies showed that the Die-I is superior to Die-II in terms of grain refinement.
\end{abstract}

\section{Keywords}

Repetitive Corrugation and Straightening, Strain Rate, Tensile Strength, Hardness, Grain Refinement

\section{Introduction}

Production of ultrafine grained (UFG)/nanostructured (NS) material for structural applications is focused by many researcher in recent times. There are two types of techniques used to produce the ultrafine grained/nanostructured materials namely top-down approach and bottom-up approach. In bottom-up approach, the nanostructured material is consolidated to the required shape by compaction. In this process the nanoparticles tend to

\footnotetext{
"Corresponding author.
} 
grow because of the higher temperature and pressure used. This bottom-up approach is unsuccessful because of the grain growth. The top-down approach, in which the coarse grained material is brought down to nanostructure, by applying severe strain to the materials [1].

Equal channel angular pressing (ECAP) [2], Accumulative roll bonding (ARB) [3], Twist extrusion (TE) [4] and Repetitive corrugation and straightening (RCS) [1] are some of the well-known top-down approaches. These processes are also called as severe plastic deformation process, in which severe strain are imparted to the material without any major change in the dimensions of the material. Among the SPD processes mentioned, ARB and RCS processes are used to produce UFG/NS in sheet like material. ARB is unsuccessful due to the lack of bonding between the stacking layers. RCS is a promising method for developing nanograined/ultrafine grained structure in the bulk sheet like materials.

Kaiping Peng et al. [5] studied the effect of die design in constrained groove pressing process, which is similar to that RCS process. They suggested a wider groove reduces the imparted stresses on the work piece, and thus allows more number of pressing cycles to achieve good mechanical and microstructural properties.

Dong Hyuk Shin et al. [6] analyzed the effect of number pressings with that of the mechanical properties of the aluminum alloy. The strain value of 0.29 is imparted after every single pressing. The microstructure is reduced to a submicron level originally from 1.2 millimeter. The hardness and the strength value is increased 20\% because of the CGP processing.

Zong-Shen Wang et al. [7] analyzed the effect of corrugation width and angle on pure nickel sheet. A twopass CGP with a groove width of $2 \mathrm{~mm}$ and a groove angle of $45^{\circ}$ has shown better mechanical properties for $\mathrm{s}$ sheet sample with a thickness of $2 \mathrm{~mm}$. They also suggested that a lower groove angle eases the intensity of shear deformation and permits more effective passes while the process efficiency is reduced. But, a higher groove width cannot induce more passes but obtain the worst CGP results. They observed, cell structures with high dislocation density in both the cases.

There are limited literatures on the effect of groove width and groove angle on mechanical and microstructural properties. Different type of RCS dies such as semicircular die and v-groove die have not compared or analyzed in the RCS processing. In this paper two different die profile such as semi groove (Die-I) and semicircular (Die-II) is taken for corrugation pressing. Here after the die will be mentioned as Die-I and Die-II throughout the paper. The mechanical properties and the microstructural properties were compared with respect to the each number of passes.

\section{Materials and Methods}

Aluminum alloy (AA 5083) was used for the RCS processing. The chemical composition of the alloy is given in Table 1.

A schematic representation of two corrugation dies are given in Figure 1. After the corrugation the aluminum alloy sheet was straightened with a pair of dies. This corrugation and straightening is called one pass. The aluminum alloy was allowed to process upto the maximum number of allowable passes.

The microstructure of the samples were examined by TEM (JEOL JEM 2100, $200 \mathrm{kV}$ ). The TEM samples were prepared by dimple grinding followed by ion milling. The tensile curve for the various RCS passed samples were obtained by INSTRON tensile testing machine. The Vickers microhardness were conducted on the surface of the flat samples using Wilson-wolpert micro hardness tester. The microhadness specimens were well polished and indentation were done along the length of the specimen at equal interval and the hardness value is averaged.

\section{Result and Discussion}

\subsection{Microhardness}

The microhardness measurements were taken on the RCS processed alloys along the direction. The average

Table 1. Composition of AA $5083 \mathrm{Al}$ alloy.

\begin{tabular}{ccccccccc}
\hline Elements & $\mathrm{Al}$ & $\mathrm{Mg}$ & $\mathrm{Si}$ & $\mathrm{Fe}$ & $\mathrm{Cu}$ & $\mathrm{Mn}$ & $\mathrm{Ti}$ \\
\hline$\%$ & 96.6 & 2.08 & 0.39 & 0.35 & 0.7 & 0.3 & 0.015 \\
\hline
\end{tabular}


microhardness values were shown in Figure 2 for the V-groove die (Figure 1) and semicircular die (Figure 2). The die-I allows the alloy to process upto 8 pass after that the surface cracks were inevitable. Whereas in Die-II, the alloy is processed upto 15 pass without due to the semi-circular profile. Also the strain imparted is very less when compared to the semi grooved profile, as a result, the Vickers microhardness is less when compared to that of the Die-II.

The Vickers microhardness has increased from 68 HV to $101 \mathrm{HV}$ when Die-I was used. And when Die-II was used, the hardness is $98 \mathrm{HV}$ at the end of 15 Passes. At initial passes the dislocation generation is maximum, which is the major reason for the improvement for the strength at initial passes. This proves that the Die-I is superior to that of the Die-II. This is because of the increased imparted strain in Die-I. At higher passes, formation of HAGBs and dislocation cells is higher, which can be proved from the TEM images.

\subsection{Stress-Strain Curve}

Figure 3 shows the variation in ultimate tensile strength with respect to the number of passes for two different die.

The parent materials showed UTS value of $200 \mathrm{MPa}$. The RCSed samples showed increased strength than the parent material. The curve shows the strength increased to 250 and 261 MPa respectively for the Die-I and DieII respectively. At the end 4th pass, the Die-I shows the highest strength of $250 \mathrm{MPa}$. But in Die-II, the maximum strength is achieved after 12th pass. In both the dies, the strength increased by $25 \%$. The failure strain were decreased with respect to the number of passes, which shows the considerable strain hardening effect due to the RCS processing in the aluminum alloy. The increase in strength with respect to the number of passes due to the reduction in grain size and due to accumulation of dislocations. The maximum strength was achieved at 4th and 12th pass for Die-I and Die-II after that the strength is reduced due to the annihilation of dislocations.

\subsection{TEM Characterization}

The TEM images for the RCS processed alloy were shown in Figure 4. Sub grain with a size of few nanometer is shown in Figure 4(a). The block dots along the GB indicates the precipitates, forms as a result of dynamic aging. Figure 4(b) shows the high angle grain boundary (HAGB) and dislocation tangle very clearly. These
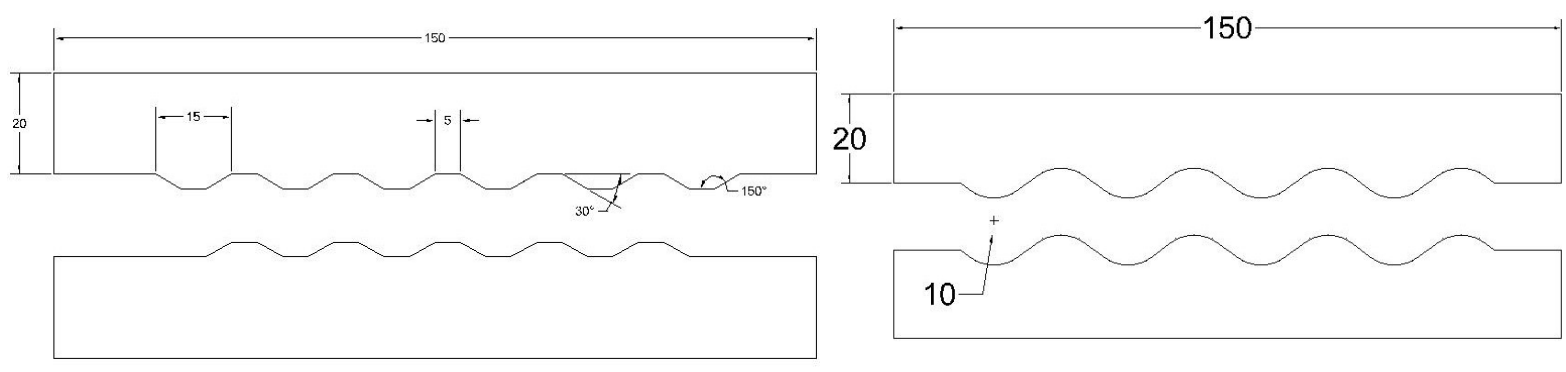

Figure 1. Two die profile showing various parameters.

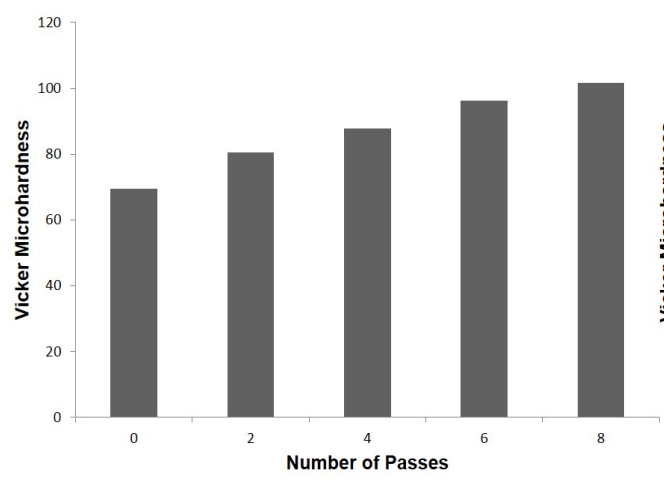

(a)

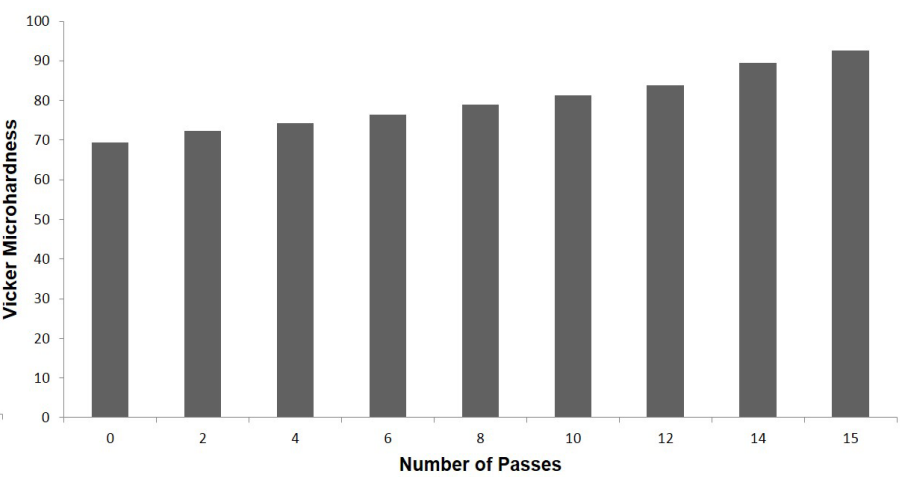

(b)

Figure 2. Vickers microhardness value for (a) Die-I (b) Die-II. 


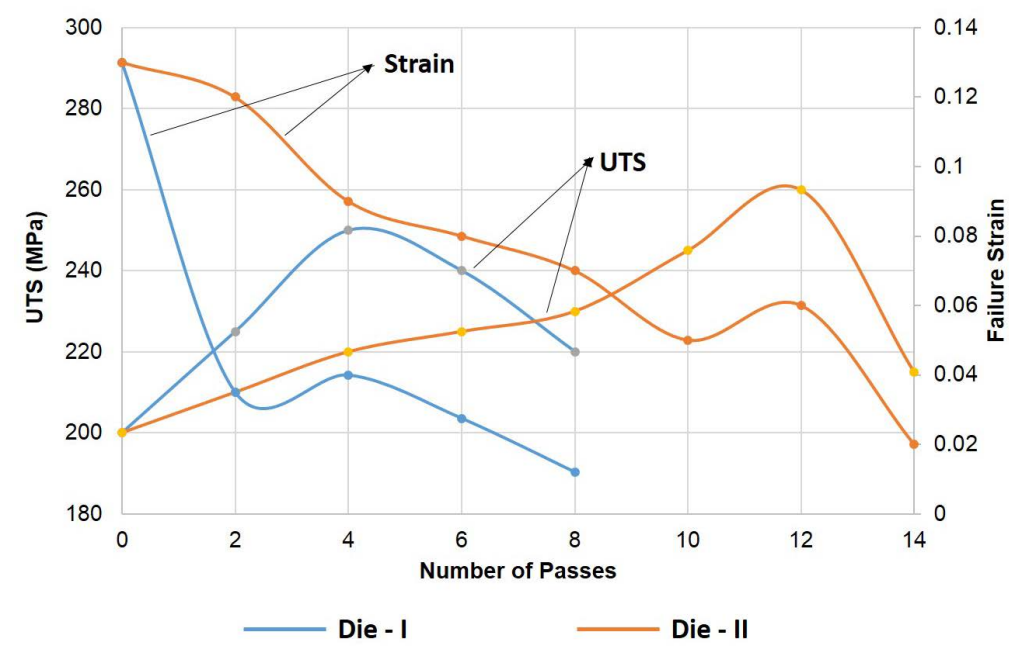

Figure 3. The variation of UTS and strain with respect to number of RCS passes.
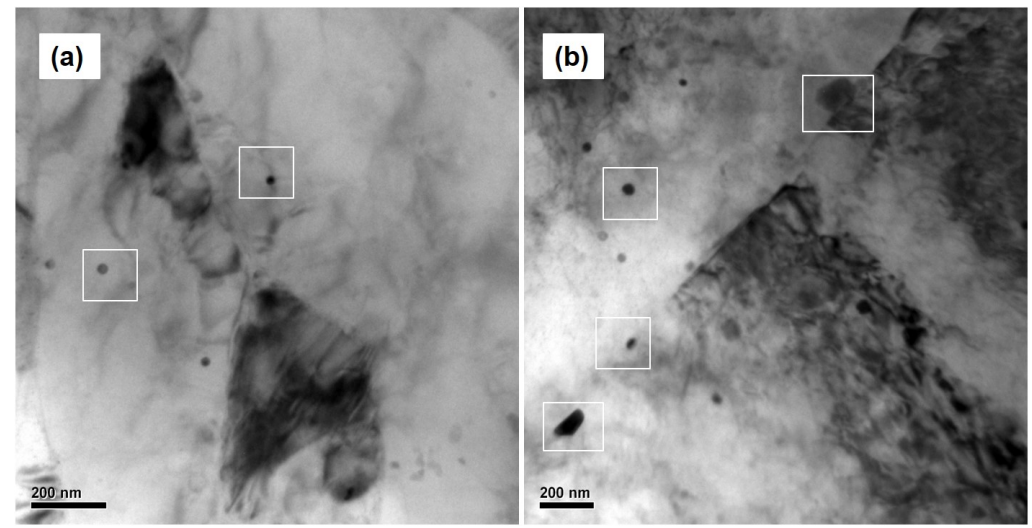

Figure 4. TEM images of AA 5083 alloy at (a) $6^{\text {th }}$ pass processed with Die-I (b) $12^{\text {th }}$ pass processed with Die-II.

HAGB and dislocations are the reason for the increase in strength and hardness.

Dynamic recovery and dynamic ageing are the important phenomena in Al-Mg alloys. The visible precipitates guarantee the occurrence of ageing process in the alloy. At higher number of passes the LAGB are recovered and forms stable HAGB/dislocation cells.

\section{Results}

Repetitive corrugation and straightening was carried out on AA 5083 alloy with two different corrugation die. These results are compared for the mechanical and microstructural properties. From the experimental results the following conclusions were drawn.

1) The UTS is increased to $250 \mathrm{MPa}$ and $261 \mathrm{MPa}$ at the end of $4^{\text {th }}$ pass and $12^{\text {th }}$ pass for Die-I and Die-II, compared to the parent material ultimate strength of $200 \mathrm{MPa}$.

2) The microhardness value increased to 1.5 times the parent material hardness because of the RCS processing. Die-I shows the maximum increase of $101 \mathrm{HV}$ after $8^{\text {th }}$ pass In Die-II, the maximum hardness is about $98 \mathrm{HV}$ at the end of $12^{\text {th }}$ pass. This shows the considerable improvement in hardness compared to the parent material hardness of $68 \mathrm{Hv}$.

3) The TEM images clearly shows the formation of dislocation cells and dislocation tangles. The dislocation cell of $100 \mathrm{~nm}$ is seen from TEM.

4) From the experimental results, it is concluded that the Die-I is superior to that of Die-II. 


\section{Acknowledgements}

N. Thangapandian thanks the Council of Science and Industrial Research, Govt. of India for a Senior Research Fellowship. One of the authors, S. Balasivanandha Prabu, acknowledges the financial support provided by The Department of Science and Technology, India (Grant No.SB/FTP/ETA-104/2012).

\section{References}

[1] Huang, J.Y., Zhu, Y.T., Jiang, H. and Lowe, T.C. (2001) Microstructures and Dislocation Configurations in Nanostructured $\mathrm{Cu}$ Processed by Repetitive Corrugation and Straightening. Acta Materialia, 49, 1497-1505. http://dx.doi.org/10.1016/S1359-6454(01)00069-6

[2] Stolyarov, V.V. and Lapovok, R. (2004) Effect of Backpressure on Structure and Properties of AA5083 Alloy Processed by ECAP. Journal of Alloys and Compounds, 378, 233-236. http://dx.doi.org/10.1016/j.jallcom.2003.10.084

[3] Saito, Y., Utsunomiya, H., Tsuji, N. and Sakai, T. (1999) Novel Ultra-High Straining Process for Bulk Materials Development of the Accumulative Roll-Bonding (ARB) Process. Acta Materialia, 47, 579-583. http://dx.doi.org/10.1016/S1359-6454(98)00365-6

[4] Beygelzimer, Y., Orlov, D. Varyukhin, V. (2002) A New Severe Plastic Deformation Method: Twist Extrusion/Ultrafine Grained Materials II. Proceedings of a Symposiuim, Held during the 2002 TMS Annual Meeting I Seattle, Washington, February, 17-21.

[5] Peng, K., Su, L., Shaw, L. and Qian, K. (2007) Grain Refinement and Crack Prevention in Constrained Groove Pressing of Two-Phase Cu-Zn Alloys. Scripta Materialia, 56, 987-990. http://dx.doi.org/10.1016/j.scriptamat.2007.01.043

[6] Hyuk, D., Park, J., Kim, Y. and Park, K. (2002) Constrained Groove Pressing and Its Application to Grain Refinement of Aluminum. Material Science Engineering A, 328, 98-103. http://dx.doi.org/10.1016/S0921-5093(01)01665-3

[7] Wang, Z.-S., Guan, Y.-J., Wang, G.-C. and Zhong, C.-K. (2015) Influences of Die Structures on Constrained Groove Pressing of Commercially Pure Ni Sheets. Journal of Material Processing and Technology, 215, 205-218. http://dx.doi.org/10.1016/j.jmatprotec.2014.08.018 